\title{
Weekly performance of maize plant under sandy soil managed with dissimilar organic materials
}

\author{
Suleiman Usman ${ }^{1}$, Abdullahi M. Maikai ${ }^{1}$, Aliyu Aminu ${ }^{1}$ and Ibrahim S. Koko ${ }^{1}$ \\ ${ }^{I}$ Natural Resources Institute, Agriculture, Health and Environment Department, University of Greenwich at \\ Medway, Chatham Maritime, Central Avenue, Chatham, ME7 4TB UK
}

\begin{abstract}
Organic materials bring many benefits to plant growth and yield performances in crop production. The objective of this study was to know the performance of maize plant from germination period to maturity period under sandy soil condition manage with different organic materials, on weekly basis. The experiment was initiated under poor sandy-soil site, just $5 \mathrm{~km}$ away from the Argungu town, Kebbi State Nigeria, located within latitude $12^{\circ} 24^{\prime \prime} \mathrm{N}$ and longitude $4^{\circ} ' 12^{\prime \prime} \mathrm{E}$. The study confirms the assumption that crop plant is very likely to perform better under poor sandy-soil condition if sustainable management requirements are provided. Plant growth and yield performances were observed positively well in the first, second, third, fourth, fifth, seven and tenth week after germination. It is concluded that sandy soil managed with organic materials provides good soil atmosphere for maize plant growth in crop production. Likewise, the results suggested that crop grown under sandy soil managed with organic materials perform better in term of plant growth and yield performances.
\end{abstract}

\section{Introduction}

It has been widely accepted that organic materials (plant and animal sources of organic matter) from plants and animals play important role in sustaining and improving soil structure, soil quality, soil function, soil health, soil fertility, and overall crop performance (growth and yield) in agricultural production. Organic materials affect physical, biological, chemical, and ecological processes in soil. They improve soil structural quality, soil water holding capacity, soil infiltration, soil organism biodiversity and soil nutrient availability (FAO, 2005). However, most of the agricultural soils in sub-Saharan Africa (SSA) are poorly fertile due to erosion, desertification and climate change impact and other related problems (Put et al., 2004; Usman, 2007). Because of these soil problems, farmers complained much about the annual yield reductions of their farm produce (Usman et al., 2012). While it is the goal of sound soil management in crop production to create a healthy soil environment which may retain balance nutrient status such that its fertility is maintained over time (Omotayo and Chukwuka, 2009). To improve the standard balance of the available soil nutrients in low fertile soils of SSA, it is necessary to be able to improve the fertility of poorly fertile soils under sustainable soil management package. This demands the use of available organic materials that are important sources of essential soil nutrients. Because when organic materials are applied in soil, they experience decomposition processes - humification and mineralization. The decomposed organic materials in soil, protect soil against runoff, erosion, mass movement of fine soil particles and enhance soil water, soil air (pore spaces), and soil productivity for wide range of crop benefit (Tieszen et al., 2001; Masri and Ryan, 2006). Indeed, organic materials are the storehouse of all essential soil and plant nutrient in soil. They are important components of soil fertility and are associated with a variety of other important soil physical, chemical, and biological characteristics (McDonald, 2010; Usman, 2013).

Use of organic materials in crop production offers numerous benefits to the agricultural development (Mäder et al., 2002; Usman, 2013). Investigating the performance of maize plant under soil treated with different organic materials could provide sustainable way of improving soil quality and high crop yield in agriculture (Usman, 2013). Problems of poor plant and yield performances are difficult to avoid under low fertile soil condition. Few studies have been conducted to investigate the weekly performances of maize plant under sandy soil condition in Kebbi State, Nigeria. This is important because of the high population increase, which demand high crop yield for better sustainable livelihood, particularly among the rural people (Usman, 2013). Our objective was to know the performance of maize plant from germination period to maturity period under sandy soil condition managed with different organic materials, on weekly basis.

\section{Materials and methods}

\subsection{Site description}

The study site, is $5 \mathrm{~km}$ away from the town city of Argungu, Kebbi State Nigeria; located within latitude $12^{\circ} 24 " \mathrm{~N}$ and longitude $4^{\circ}$ ' $12 " \mathrm{E}$. The common agricultural activity is mono-cropping under poor land, characterised by aridic (dried) and hot soil moisture and temperature characteristics. The topography of the site is flat (visible at $1-10 \mathrm{~m}$ ) belonging to soil group Aridisols under FAO-USDA classification systems (FAO, 
2006; Soil Survey Staff, 2010). The surface soil of the site is physically characterised by few indication of sheet erosion under scattered tree vegetation cover. The geo-physical properties and dynamic conditions of the soil of the farm site are presented in Table 1.

Table 1: The summary of geo-physical properties and dynamic condition of study site

\begin{tabular}{|c|c|c|c|c|c|}
\hline Physical & & Biological & & Soil conditions & \\
\hline Characteristics & Proportion & Properties & Observed & Properties & $\underline{\text { Extent }}$ \\
\hline Sand & $66 \%$ & Crust & Mat-like & $\overline{\text { Water erosion }}$ & $\overline{\text { Slight }}$ \\
\hline Silt & $16 \%$ & & Termite-build & Wind erosion & Moderate \\
\hline Clay & $10 \%$ & & Ant-build & Surface soil damages & Moderate \\
\hline Organic matter & $8 \%$ & & & Vegetation cover & Poor \\
\hline Bulk density & $1.43 \mathrm{~cm} / \mathrm{g}$ & Soil biota & Arthropods & Desertification & Less \\
\hline Soil colour & Light-ash & & Termite & Overgrazing & Moderate \\
\hline Soil structure & Granular & & & Deforestation & Severe \\
\hline Soil texture & Loam-sand & Other & Insect cast & Sand-stony & Absent \\
\hline Soil consistence & Loose & & Discrete bodies & Rock-outcrop around & Absent \\
\hline
\end{tabular}

\subsection{Experimental soil management exercise}

A field-crop experiment was designed to test the plant growth and yield performance of local maize seeds under 12 different soil strata which have been sustainably managed with different organic materials. In the process of this soil management exercise, a stratified random sampling was used (Upton, 1987). The field site was divided into a number of strata (groups); each stratum consists of the same soil and climate conditions, the same agricultural and management activities under poor sandy-soil condition. There are 12 different soil strata, which were designed and each has five representative soil units. These strata were provided with specific field codes as: S-cow01, S-sheep02, S-goat03, S-donkey04, S-rice-husk05, S-millet-husk06, S-albida07, S-nilotica08, S-wood-ash09, S-wood-husk10, S-house-refuse11, and S-ani-cro-ber12. The control strata unit has no code. Still, all the strata were treated separately with specific organic sample. Soil holes were dug $(40 \mathrm{~cm}$ length $\mathrm{x} 30$ $\mathrm{cm}$ depth) in each soil unit. Organic samples were supplied to these holes and about $1000 \mathrm{ml}$ of water was poured twice every day (morning and evening) for one week. This is to enhance the proper decomposition of organic materials in soil. The experiment lasted for a period of three weeks, consecutively.

\subsection{Field-crop direct observation test}

Direct Observation Method (DOM) that involves regular visiting of every number of plant cultivar was used (Upton, 1987). The control soil unit was taken separately. However, a sample representative of each stratum was measured on weekly basis. The parameters used in this measurement exercise are: stem height, stem size, leaf size, leaf length and number of leaf for plant growth performances (Figure 1). While the number of seed per corn, number of lines per corn, and shapes of seed in each corn were used for yield performances' assessment as designed (Figure 1). Besides, the measurements of plant parameters were made by means of plastic ruler, and data were recorded accordingly. The intervals for all the measurements are: after 1 week (19/07/2011-26/07/2011), after 3 weeks (19/07/2011-10/08/2011), after 5 weeks (19/07/2011-24/08/2011), after 7 weeks (19/07/2011 - 07/09/2011), and after 10 weeks (19/07/2011-28/09/2011). Corn yield was finally harvested on 30 October, 2011 after 102 days (15 weeks). The corn harvested was used to determine the number of seed per each corn as well as the number of seeds on each corn. The complete data may be seen in Appendix.
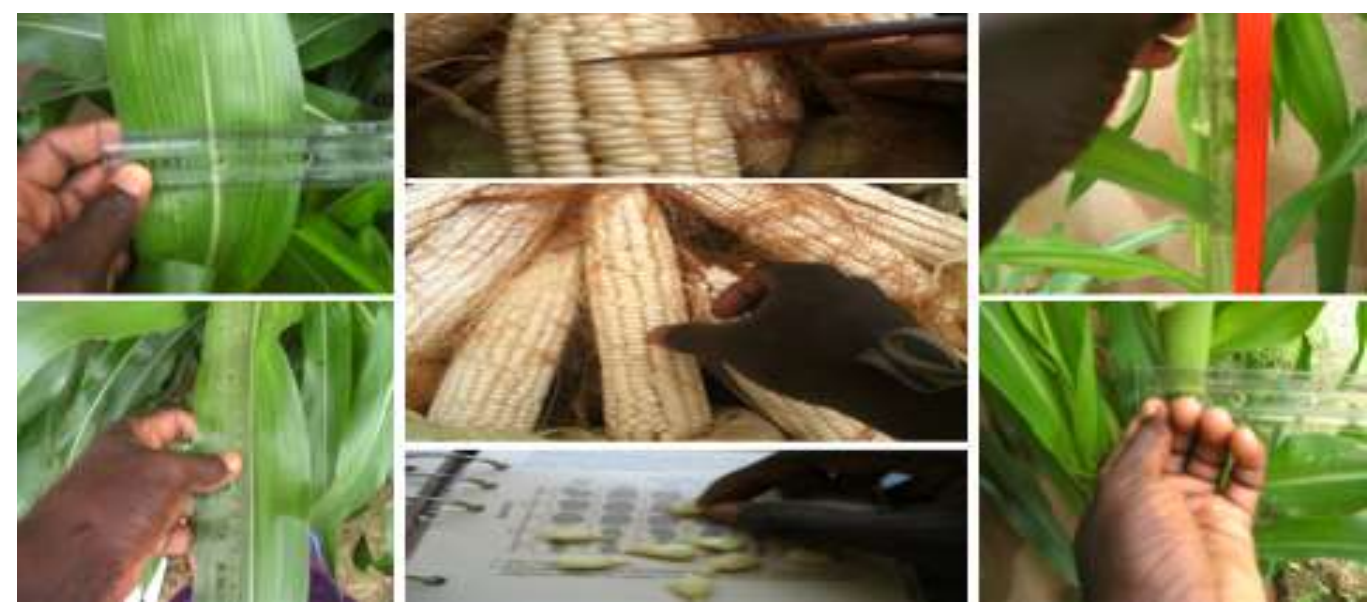

Figure 1: Typical illustrations of crop direct observation method used 


\subsection{Data analyses}

All data collected on plant growth and yield performance were analysed by ANOVA and regression analysis $\mathrm{R}^{2}$ (Verzani, 2002; Nacson, 2007). The first analysis is grouped into $1^{\text {st }}, 2^{\text {nd }}, 3^{\text {rd }}, 4^{\text {th }}$ and $5^{\text {th }}$. Variance (VAR) was used as measure of the entire plant growth's variability, standard deviation (SD) as the square root of this variability and mean as a measure 'precision' of an estimate of the true population average. The differences in term of VAR and SD on weekly bases were determined and defined as: ¥ 'significant differences’, $\Psi$ 'non-significant differences' and $¥$ 'minor differences'. In the second analysis, $\mathrm{R}^{2}$ was used to show the proportion of common variation in all the plant performances for future prediction of the results outcome. $\mathrm{R}^{2}$ value called the coefficient of determination was calculated. This value was also used to show the "strength" or "magnitude" of the relationship between all the parameters measured.

\section{Results}

The analyses of the results of weekly plant growth performance of maize cultivar under 12 different soil strata are given in Tables $2,3,4,5$ and 6 covering $1^{\text {st }}, 2^{\text {nd }}, 3^{\text {rd }}, 4^{\text {th }}$ and $5^{\text {th }}$ analysis. In the $1^{\text {st }}$ analysis (Table $2)$, the VAR $(2.511730057 \psi)$ and SD $(2.511730057 \psi)$ show no differences in term of plant height under all the soil strata, however, these plants were differ significantly for plant leaf length $(\mathrm{SD}=7.264963659 ¥$, VAR $=$ $52.77969697 ¥)$. Similarly, they are not significantly different for plant leaf size (SD $=0.498907898 \nsucceq, \mathrm{VAR}=$ $0.248909091 \nsucceq)$, and number of leaf per plant $(\mathrm{SD}=1.678744119 \nsucceq, \mathrm{VAR}=2.818181818 \nsucceq)$.

Table 2: Performances of maize plant growth after 1 week of seeds germination

\begin{tabular}{lllll}
\hline $\mathbf{1}^{\text {st }}$ Analysis & $\begin{array}{l}\text { Stem height } \\
(\mathbf{c m})\end{array}$ & $\begin{array}{l}\text { Leaf length } \\
(\mathbf{c m})\end{array}$ & $\begin{array}{l}\text { Leaf size } \\
(\mathbf{c m})\end{array}$ & $\begin{array}{l}\text { No. of leaf } \text { plant }^{-\mathbf{1}} \\
(\mathbf{c m})\end{array}$ \\
\hline Sum & 61 & 179.8 & 14.2 & 42 \\
Mean & 5.083333333 & 14.98333333 & 1.290909091 & 3.5 \\
SD & $2.511730057 \Psi$ & $7.264963659 ¥$ & $0.498907898 \nsucceq$ & $1.678744119 \nsucceq$ \\
VAR & $2.511730057 \Psi$ & $52.77969697 ¥$ & $0.248909091 \nsucceq$ & $2.818181818 \nsucceq$ \\
MAX & 8.1 & 22.2 & 1.8 & 5 \\
MIN & 5.1 & 15.6 & 1.1 & 4 \\
\hline
\end{tabular}

Reminder note: $\Psi$ means no significant different, ¥ means there is significant different, ¥ means there is different but not significantly

In the $2^{\text {nd }}$ and $4^{\text {th }}$ analyses (Tables 3,4 ), all the four parameters (i.e. stem height, stem size, leaf length, and number of leaf per plant) show significant differences (¥) after three and seven weeks of plant’s growth development. In these two analyses, only the plant's leaf sizes show a kind of relationship with each other, although, there is a difference of $0.1 \mathrm{~cm}$ between the value of SD $(0.872648355 \nsucceq)$ and that of VAR $(0.761515152 \mathrm{Y})$ in the $2^{\text {nd }}$ analysis, as well as in the $4^{\text {th }}$ analysis $(\mathrm{SD}=0.886873979 \nsucceq$ and VAR $=$ 0.786545455 y). During these seven weeks periods, the leaf sizes of maize plants were grown on the same performances.

Table 3: Performances of maize plant growth after 3 weeks of seeds germination

\begin{tabular}{llllll}
\hline $\mathbf{2}^{\text {nd }}$ & $\begin{array}{l}\text { Stem height } \\
\text { Analysis }\end{array}$ & $\begin{array}{l}\text { Stem size } \\
(\mathbf{c m})\end{array}$ & $\begin{array}{l}\text { Leaf length } \\
(\mathbf{c m})\end{array}$ & $\begin{array}{l}\text { Leaf size } \\
(\mathbf{c m})\end{array}$ & $\begin{array}{l}\text { No. of leaf } \text { plant }^{\mathbf{1}} \\
(\mathbf{c m})\end{array}$ \\
\hline Sum & 101.9 & 8 & 362.1 & 29.8 & 77 \\
Mean & 8.491666667 & 0.666666667 & 30.175 & 2.483333333 & 6.416667 \\
SD & $3.116950238 ¥$ & $0.253460893 ¥$ & $10.59108759 ¥$ & $0.872648355 ¥$ & $2.234373 ¥$ \\
VAR & $9.715378788 ¥$ & $0.064242424 ¥$ & $112.1711364 ¥$ & $0.761515152 ¥$ & $4.992424 ¥$ \\
MAX & 11.8 & 0.9 & 38.8 & 3.1 & 8 \\
MIN & 6.1 & 0.4 & 22.6 & 1.8 & 5 \\
\hline
\end{tabular}

Reminder note: $¥$ means significant different, $¥$ means there is different but not significantly

Table 4: Performances of maize plant growth after 7 weeks of seeds germination

\begin{tabular}{llllll}
\hline $3^{\text {rd }}$ & $\begin{array}{l}\text { Stem height } \\
\text { Analysis }\end{array}$ & $\begin{array}{l}\text { Stem size } \\
(\mathbf{c m})\end{array}$ & $\begin{array}{l}\text { Leaf length } \\
(\mathbf{c m})\end{array}$ & $\begin{array}{l}\text { Leaf size } \\
(\mathbf{c m})\end{array}$ & $\begin{array}{l}\text { No. of leaf } \\
(\mathbf{c m})\end{array}$ \\
\hline Sum & 427.2 & 19.9 & 710.5 & 67.8 & 117 \\
Mean & 38.83636364 & 1.809090909 & 64.59090909 & 6.163636364 & 10.63636364 \\
SD & $6.539613555 ¥$ & $0.326969557 \nsucceq$ & $6.619283125 ¥$ & $0.886873979 \nsucceq$ & $1.361816968 \nsucceq$ \\
VAR & $42.76654545 ¥$ & $0.106909091 ¥$ & $43.81490909 ¥$ & $0.786545455 \nsucceq$ & $1.854545455 \nsucceq$ \\
MAX & 52.6 & 2.4 & 76.2 & 7 & 12 \\
MIN & 33 & 1.5 & 56.8 & 5 & 9 \\
\hline
\end{tabular}

Reminder note: ¥ means significant different, $¥$ means there is different but not significantly 
In the $3^{\text {rd }}$ and $5^{\text {th }}$ analyses (Tables: 5, 6), the differences between all the maize plants on leaf size and number of leaf per plant performances are also not significant. Considerably, in $3^{\text {rd }}$ analysis, the SD is $0.506503163 ¥$ and VAR is $0.256545455 ¥$ for leaf sizes, and SD is $0.750757194 ¥$ and VAR is $0.563636364 ¥$ for number of leaf per plant. In this regard, difference of $0.2 \mathrm{~cm}$ was observed on plant's leaf sizes as well as number of leaf per plants accordingly. While in the $5^{\text {th }}$ analysis, where the value of SD is $0.599090219 \nsucceq$, VAR is $0.358909091 \nsucceq$ for leaf size, and SD is $0.8202 \bigvee$, VAR is $0.672727 \nsucceq$ for number of leaf per plant, the difference of 0.2 and 0.1 $\mathrm{cm}$ were observed for all the plants. This shows that there is significant relationship between all the organic materials used in this experiment in respect to soil quality management and crop growth performances as well.

Table 5: Performances of maize plant growth after 5 weeks of seeds germination

\begin{tabular}{|c|c|c|c|c|c|}
\hline $\begin{array}{l}4^{\text {th }} \\
\text { Analysis }\end{array}$ & $\begin{array}{l}\text { Stem height } \\
\text { (cm) }\end{array}$ & $\begin{array}{l}\text { Stem size } \\
(\mathrm{cm})\end{array}$ & $\begin{array}{l}\text { Leaf length } \\
(\mathrm{cm})\end{array}$ & $\begin{array}{l}\text { Leaf size } \\
(\mathrm{cm})\end{array}$ & $\begin{array}{l}\text { No. of leaf plant } \\
\text { (cm) }\end{array}$ \\
\hline Sum & 159.6 & 14 & 558.6 & 50.2 & 90 \\
\hline Mean & 14.50909091 & 1.272727273 & 50.78181818 & 4.563636364 & 8.181818182 \\
\hline SD & $1.789108463 ¥$ & $0.179392916 \nsucceq$ & $4.510613746 ¥$ & $0.506503163 ¥$ & $0.750757194 \ngtr$ \\
\hline VAR & $3.200909091 ¥$ & $0.032181818 \nsucceq$ & $20.34563636 ¥$ & $0.256545455 ¥$ & $0.563636364 \nsucceq$ \\
\hline MAX & 18.1 & 1.6 & 58.6 & 5.3 & 10 \\
\hline MIN & 12.3 & 1 & 43.7 & 3.8 & 7 \\
\hline
\end{tabular}

Reminder note: $¥$ means significant different, $¥$ means there is different but not significantly

Table 6: Performances of maize plant growth after 10 weeks of seeds germination

\begin{tabular}{|c|c|c|c|c|c|}
\hline $\begin{array}{l}5^{\text {th }} \\
\text { Analysis }\end{array}$ & $\begin{array}{l}\text { Stem height } \\
(\mathrm{cm})\end{array}$ & $\begin{array}{l}\text { Stem size } \\
(\mathrm{cm})\end{array}$ & $\begin{array}{l}\text { Leaf length } \\
(\mathrm{cm})\end{array}$ & $\begin{array}{l}\text { Leaf size } \\
(\mathrm{cm})\end{array}$ & $\begin{array}{l}\text { No. of leaf } \\
\text { plant }^{-1}(\mathrm{~cm})\end{array}$ \\
\hline Sum & 884.6 & 25.1 & 763.6 & 73.8 & 126 \\
\hline Mean & 80.41818182 & 2.281818182 & 69.41818182 & 6.709090909 & 11.45455 \\
\hline SD & $20.82593663 ¥$ & $0.31246818 \nsucceq$ & $6.843656652 ¥$ & $0.599090219 \nsucceq$ & $0.8202 \nsucceq$ \\
\hline VAR & 433.7196364¥ & $0.09763636 ұ$ & $46.83563636 ¥$ & $0.358909091 \nsucceq$ & $0.672727 \nsucceq$ \\
\hline MAX & 120 & 2.8 & 79.7 & 7.8 & 12 \\
\hline MIN & 54.4 & 1.9 & 60.8 & 6.1 & 10 \\
\hline
\end{tabular}

Reminder note: ¥ means significant different, $¥$ means there is different but not significantly

However, in comparison, after $1^{\text {st }}$ week, the maximum stem height is 8.1 and was increased to 11.8, 18.1, 52.6 and $120 \mathrm{~cm}$ after $3^{\text {rd }}$ week (Table 3 ), $5^{\text {th }}$ week (Table 5), $7^{\text {th }}$ week (Table 4) and $10^{\text {th }}$ week (Table 6), respectively. This means the differences of $3.7,6.3,34.5$ and $67.4 \mathrm{~cm}$ were observed after week 1 , week 3 , week 5 , week 7 and week 10 of plant growth respectively. The minimum of 5.1, 6.1, 12.3, 33 and $54.4 \mathrm{~cm}$ were recorded for the entire stem height in which the mean of 5.1, 8.5, 14.5, 38.8 and $80.4 \mathrm{~cm}$ were determined. Similarly there were differences in term of maximum and minimum values between week 1 , week 3 , week 5 , week 7 and week 10 for all the stem size, leaf length, leaf size and number of plant leaf parameters (Tables: 2, 3, 4, 5 and 6). However, the yield performances of all the plants growths are shown in Table 7.

Table 7: Yield performances of maize plants under 12 different soil strata

\begin{tabular}{llll}
\hline Soil strata & $\begin{array}{l}\text { Number of seed lines } \\
\text { on corn }\end{array}$ & $\begin{array}{l}\text { Number of seed per } \\
\text { corn }\end{array}$ & Shapes of seeds on corn \\
\hline S-cow01 & 13 & 581 & Reticulate (medium size) \\
S-sheep02 & 12 & 576 & Reticulate (medium size) \\
S-goat03 & 16 & 608 & Rounded ball (big size) \\
S-donkey04 & 14 & 616 & Rounded spherical (big size) \\
S-rice-husk05 & 12 & 564 & Plate-like (big size) \\
S-millet-husk06 & 20 & 700 & Spherical crudely (small size) \\
S-albida07 & 13 & 611 & Reticulate (medium size) \\
S-nilotica08 & 10 & 440 & Plate-like (big size) \\
S-wood-ash09 & 14 & 518 & Dentrictic branched (small size) \\
S-wood-husk10 & - & - & - \\
S-house-refuse11 & 12 & 696 & Cylindrical (medium size) \\
S-ani-cro-ber12 Control & 18 & 846 & Reticulate (medium + big sizes) \\
& 8 & 281 & Plate-like (small size) \\
\hline
\end{tabular}

According USDA-NRCS (2002) guidelines (see Appendix No. 1) 
According to Table 7, S-ani-cro-ber12, S-millet-husk06 and S-house-refuse11 show high positive yield performance of 846, 700 and 696 number of seed on corn respectively. However, 616, 611, 608, 581, 576, 564, 518 and 440 are recorded under S-donkey04, S-albida07, S-goat03, S-cow01, S-sheep02, S-rice-husk05, Swood-ash09 and S-nilotica08 respectively. In this regard, S-millet-husk06 has the highest number of seed line on each corn and S-nilotica08 has the lowest number (Table 7). By comparison, all the soil stratum units show better performance than the control strata unit, although some similarity was noted in term of seed shape. The shapes and sizes of all the seeds on the corns differ greatly and classified as reticulate (medium size), rounded ball (big size), rounded spherical (big size), plate-like (big size), spherical crudely (small size), dentrictic branched (small size), and cylindrical (medium size). The different accounted for by the seeds shapes and sizes under this assessment would be use in farm labour cost analysis, farm profit analysis, weight $(\mathrm{kg})$ measurement in market business analysis, quantity yield analysis, and storage management system. Generally, no record was taken under S-wood-husk10 because of seed failure to germinate after planting. The reason behind this failure is unknown but after 2 weeks of planting, the seeds planted were found infected (no evidence has been seen but it appeared that the seed look like-burnt). There are significant improvements for all the soil strata treated with organic materials if compared with control treatment $(8,281$ for number of seed lines on corn and number of seed per corn).

Examining the degree of relationships between the parameters measured, further observation is possible using regression analysis. The analysis shows that the numbers of stem height, stem size, leaf length, leaf size and number of plant leaf for all the maize plants growth under 11 soil strata are deviated in the same directions but behave in different ways. Partly this was due to the function of organic materials used under the soil strata in which all the plants was grown. It appeared that after one week of plant growth, the numbers of leaf length for all the plants measured are positively same $\left(\mathrm{y}=1.1494 \mathrm{x}+9.2398 \mathrm{R}^{2}=0.5103\right)$. There are also positive performance on stem height $\left(y=0.4205 x+2.9461 \mathrm{R}^{2}=0.5562\right)$ and number of leaf per plant $(\mathrm{y}=$ $\left.0.2034 x+2.9461 R^{2}=0.304\right)$, but the extent of these performances is difficult to verify (Figure 60). Reasonably, there is no relationship between the numbers of leaf size for all the plants $\left(y=0.0176 x+1.3022 R^{2}\right.$ $=0.0472)$. Similarly there was also positive performances in term of stem height $\left(y=0.1998 x+5.8611 R^{2}=\right.$ $0.3996)$, leaf length $\left(y=1.178 x+26.425 R^{2}=0.5907\right)$ and number of leaf per plants $\left(y=0.3257 x+7.2437 R^{2}=\right.$ $0.4203)$ after 3 weeks of plant growth. However, in the case of leaf size $\left(y=0.0729 x+2.2843 R^{2}=0.3246\right)$ and stem size $\left(y=0.0356 x+0.5172 \mathrm{R}^{2}=0.5862\right)$ this positive performance is lacking. In contrast, some deviations were observed in term of leaf sizes and number of plant leaf after week 5 and week 7 of plant growths. However, a rapid growth has been seen for all the plant growth components throughout the 7 week period but remained positively fixed after 10 week. Generally, over all the soil strata, the regression analysis for plant growth performance can be categorised into four linear relationships (Table 8): week linear relationships, very week linear relationships, poor linear relationships and very poor linear relationships.

Table 8: Statistical data on correlation analysis of maize plant growth performances

\begin{tabular}{|c|c|c|c|c|c|}
\hline Test & $\begin{array}{l}\text { Stem height } \\
\text { (cm) }\end{array}$ & $\begin{array}{l}\text { Stem size } \\
(\mathrm{cm})\end{array}$ & $\begin{array}{l}\text { Leaf length } \\
(\mathrm{cm})\end{array}$ & $\begin{array}{l}\text { Leaf size } \\
(\mathrm{cm})\end{array}$ & $\begin{array}{l}\text { No. of leaf per plant } \\
(\mathrm{cm})\end{array}$ \\
\hline After week 1 & $\mathrm{R}^{2}=0.5562$ & - & $\mathrm{R}^{2}=0.5103$ & $\mathrm{R}^{2}=0.0472$ & $\mathrm{R}^{2}=0.304$ \\
\hline After week 3 & $\mathrm{R}^{2}=0.3996$ & $\mathrm{R}^{2}=0.5862$ & $\mathrm{R}^{2}=0.5907$ & $\mathrm{R}^{2}=0.3246$ & $\mathrm{R}^{2}=0.4203$ \\
\hline After week 5 & $\mathrm{R}^{2}=0.4196$ & $\mathrm{R}^{2}=0.1504$ & $\mathrm{R}^{2}=0.4507$ & $\mathrm{R}^{2}=0.0538$ & $\mathrm{R}^{2}=0.0559$ \\
\hline After week 7 & $\mathrm{R}^{2}=0.0593$ & $\mathrm{R}^{2}=0.0079$ & $\mathrm{R}^{2}=0.2453$ & $\mathrm{R}^{2}=0.1041$ & $\mathrm{R}^{2}=0.1545$ \\
\hline After week 10 & $\mathrm{R}^{2}=0.0922$ & $\mathrm{R}^{2}=0.0493$ & $\mathrm{R}^{2}=0.0453$ & $\mathrm{R}^{2}=0.0171$ & $\mathrm{R}^{2}=0.1635$ \\
\hline
\end{tabular}

The values of $>0.5$ under stem height $\left(R^{2}=0.5562\right)$, stem size $\left(R^{2}=0.5862\right)$ and leaf length $\left(R^{2}=0.5103,=\right.$ $0.5907)$ show a week linear relationships. However, values $<0.5$ to 0.1 under stem height $\left(\mathrm{R}^{2}=0.4196,=\right.$ $0.3996)$, stem size $\left(R^{2}=0.1504\right)$, leaf length $\left(R^{2}=0.4507, R^{2}=0.2453\right)$, leaf size $\left(R^{2}=0.3246\right)$ and number of plant leaf $\left(R^{2}=0.4203,0.1635,0.1545\right)$ show very week relationships. While values $<0.1$ under stem height $\left(R^{2}\right.$ $=0.0922,=0.0593)$, stem size $\left(R^{2}=0.0493\right)$, leaf length $\left(R^{2}=0.0453\right)$, leaf size $\left(R^{2}=0.0171\right)$ and number of plant leaf $\left(\mathrm{R}^{2}=0.0559\right)$, shows poor linear relationships. The last type of linear is very poor relationship and was observed under stem size $\left(\mathrm{R}^{2}=0.0079\right)$ at 7 week of plants growth. Over all the crop yield performances, the regression analysis shows positive correlation in for number of seed in corn $\left(y=11.182 \mathrm{x}+547.09 \mathrm{R}^{2}=\right.$ $0.1222)$ and negative correlation for number of line in corn $\left(0.1091 \mathrm{x}+13.345 \mathrm{R}^{2}=0.0152\right)$.

\section{Discussion}

While it was expected that only few organic materials are likely to be the best sources of organic matter for soil quality and soil fertility functions, however, the results of field test carried out in Kebbi State Nigeria show that there are many important sources of soil organic matter in the region. The results of this finding have further confirm the better performance of plant growth and yield productivity under soil treated with organic 
materials as similarly reported in previous studies (e.g. Janssen and van der Weert, 1977; Basu et al., 2007; Fan et al., 2012). Throughout the period of pant growth (106 days), all the plants seem to have grown perfectly without any physical deformity. The parameters measured conformed very well with the work of Basu et al. (2007). The performances of plant growth in term of stem height and leaf length show a remarkable attraction for using plant and animal organic materials under poor soil conditions. There was rapid improvement in term of stem height, stem size, leaf length, leaf size and number of plant leaf from germination to maturity period. The analyses of variance and standard deviation show clear differences of all the plants (Tables $2-6$ ). In the $1^{\text {st }}$ analysis, the average mean for stem height, leaf length, leaf size and number of plant leaf are approximately 5.1, $14.9,1.3$ and $3.5 \mathrm{~cm}$ respectively. Absolutely there were rapid increased of plant growth performance in the $3^{\text {rd }}$ week $($ mean $=8.5,30.1,2.5$ and $6.4 \mathrm{~cm}), 5^{\text {th }}$ week $($ mean $=14.5,50.8,4.6$ and $8.2 \mathrm{~cm}), 7^{\text {th }}$ week $($ mean $=38.8$, 64.6, 6.2 and $10.6 \mathrm{~cm}$ ) and $10^{\text {th }}$ week $($ mean $=80.4,69.4,6.7$ and $11.5 \mathrm{~cm})$. This also has reflected the sum, variance, standard deviation, minimum and maximum number of stem height, stem size, leaf length, leaf size and number of plant leaf accordingly (Figures 2, 3).

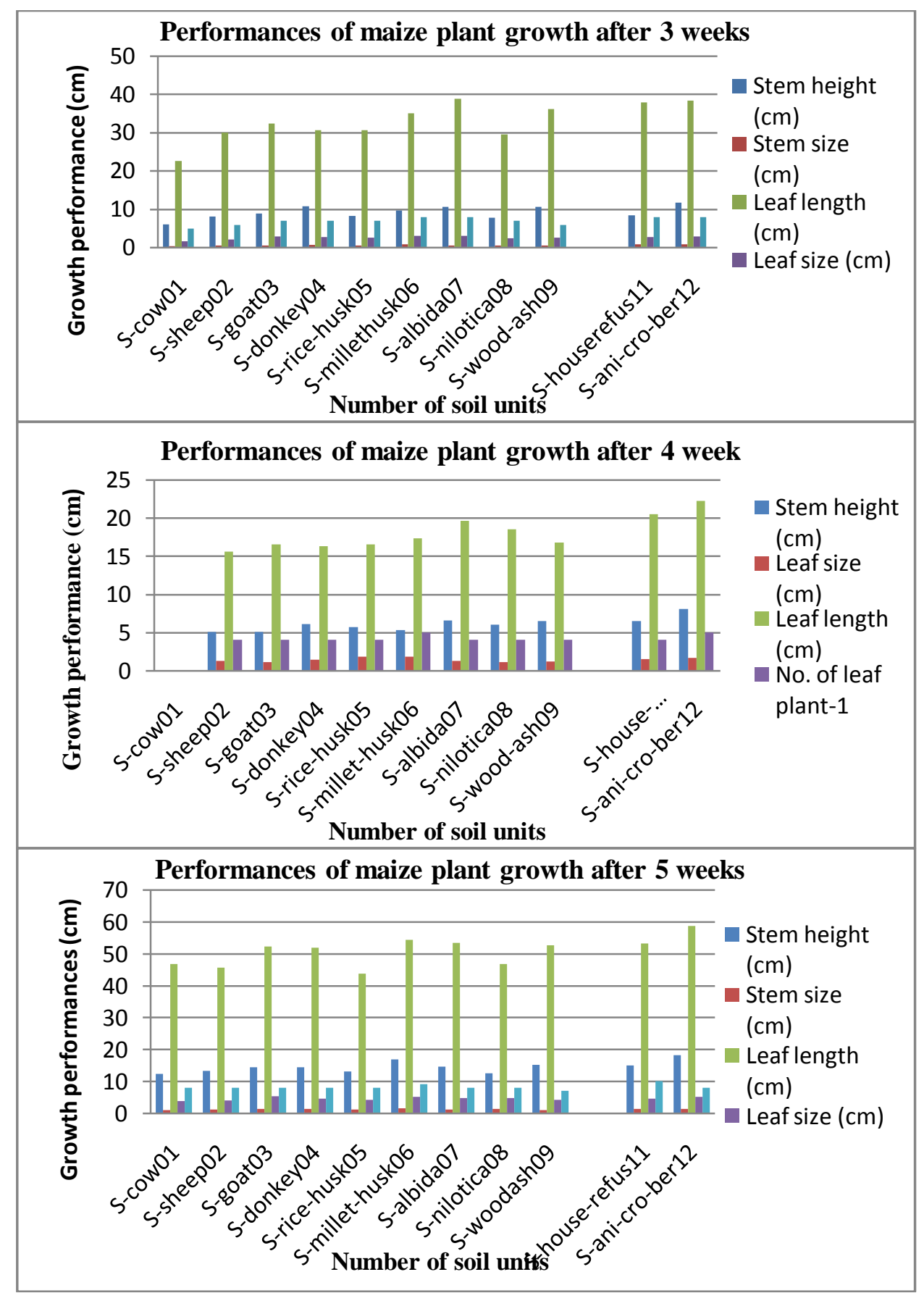

Figure 2: Differences of maize plant growth performances under 11 different soil units 
Initially after $1^{\text {st }}$ week, $3^{\text {rd }}$ week and $5^{\text {th }}$ week of planting, the plant growth performances under 11 soil strata remained the same for all the parameters except for the stem height and leaf length (Figure 2). The highest positive performance in term of these two parameters by ranks is soil strata 12 and 11 . The probable reason for their high performance was due to high concentration of nitrogen uptake which is high in ani-cro-ber and house refuse organic materials (Table 6). Absolute growth performance of leaf size and number of plant leaf was positively the same in all strata. Basu et al. (2007) have reported higher leaf area index and nodule numbers under soil treated with integrated application of three organic materials. FAO (2005) theorized that wellintegrated organic materials provide as many essential nutrients for proper plants growth compared with the single organic (plant/animal) material. In contrary, after $7^{\text {th }}$ and $10^{\text {th }}$ weeks of planting, optimum increase of high growth performances in term of stem height and leaf length was also positive in soil strata 4 and 6 but not as high as soil strata 12 and 11 (Figure 3). However, no considerable changes in respect of leaf size, stem size and number of plant leaf were observed for all the 11 soil strata.

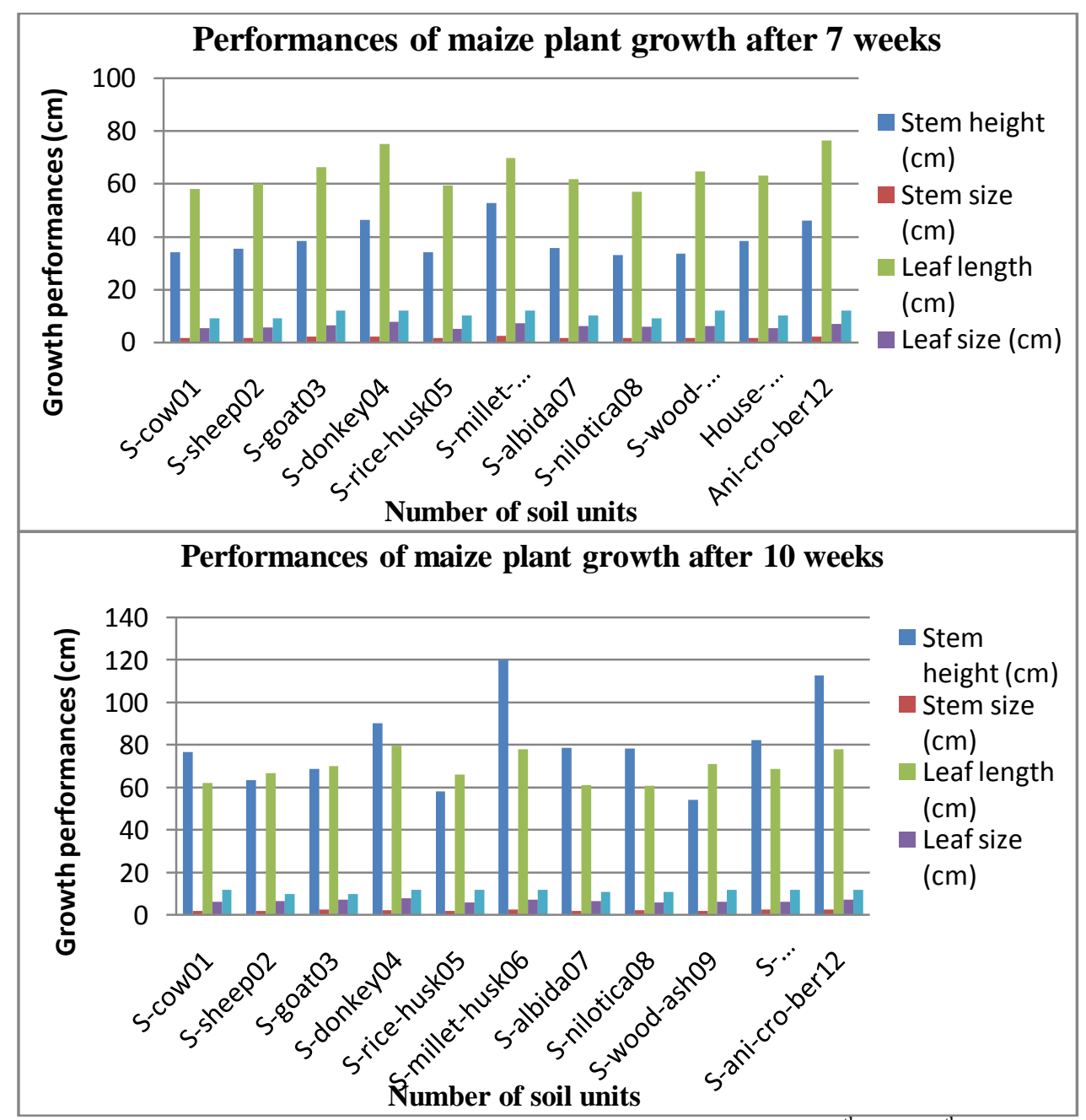

Figure 3: Performances of maize plants growth under soil strata $7^{\text {th }}$ and $10^{\text {th }}$ week

On the other hand, high yield in crop production has been of great priority to all farmers in the Kebbi State (KARDA, 2009). In the present study, it has been shown that yields have differed between the soil strata. Positively, the result will be of consideration to farmers in Kebbi State because of its economic importance in term of yield performance (Table 7). This yield performance has been used in the interpretation of the functions of different organic materials in crop production (Basu et al., 2007). Janssen and van der Weert (1977) reported that the use of organic materials under soil quality management in crop production provided a high yield performance than long term inorganic fertilizer application. Although, the present study has not been design to compare the crop yield performance under soil treated with organic materials and inorganic fertilizers, however, it is believe that plant grown in soil treated with organic materials performed well in term of crop yield, seed healthy and seed vigour (Jeffery, 2008; Caires, et al., 2011). Besides performed well, it is also believe that maize yield under soil treated with different organic materials is rewarding, economic and long term benefits 
(Jeffery, 2008). In the present study the effect of maize yield under different soil strata shows an economic benefit of organic materials in crop production. This benefit of organic contributions was reported to improve maize growth and also provide long term recovery for the proper crop performance under drought condition (Vanlauwe et al., 2001). In line with this advantages of organic materials in agriculture, it is important to note that plants grown in soils treated with bulked of all organic materials (ani-cro-ber), millet husks and housed refuse have performed better (number of seed on corn $=846,700$ and 696 respectively) compared with plant grown in soil treated with animal dung (number of seed on corn $=616,608,581$ and 576 for Soil strata 04, 03, 01 and 02 respectively (Figure 4). One of the possible reasons of the high number of seeds per each corn is longterm effects such as weed competitions, which remain unknown in the last three weeks to crop maturity. Berner et al. (2002) have similarly noted low weed competition with reduce tillage under soil organic management. The present study was completely carried out under zero tillage as in line with observation made by Berner et al. (2002).

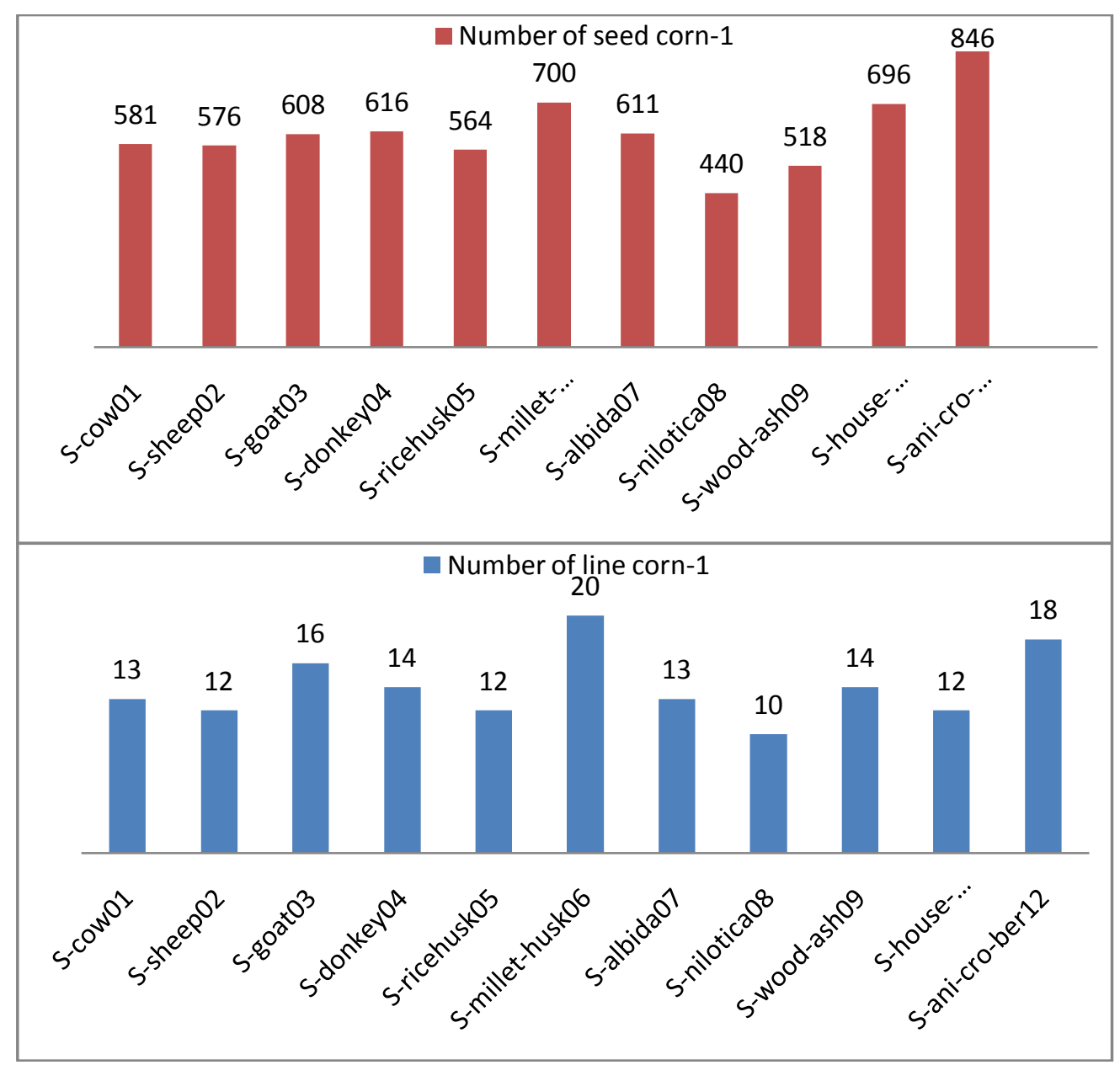

Figure 4: Yield performance of maize plant under different soil units after 106 days

There is a close relationship between the maize yield performance observed from soil stratum treated with donkey dung and the one treated with Acacia albida. The number of seed line on corn for these two soil strata is 14 and 13 whereas the number of seed on corn is 616 and 611 respectively. However, they differed significantly in term of seed shape, rounded spherical (big size) for S-donkey04 and reticulate (medium size) for S-albida07. Similarly, 0the reticulate seed shape was also observed for S-ani-cro-ber12, S-cow01 and S-sheep02. This type of seed classification was considered as important factor in shaping the geographical distributions of crop diversity (van Etten and de Bruin, 2007), as well as the foundation of farmers practice of selecting seed from the previous harvest and saving it for the next planting season (Badstuea et al., 2007).

\section{Conclusion}

In conclusion, the present study confirms the assumption that crop plant is very likely to perform better under poor sandy-soil condition if management requirements are provided. Plant growth and yield performances were reported positively well in first, second, third, fourth, fifth, seven and tenth week after germination. We 
conclude that sandy soil managed with organic materials provides a good soil atmosphere for maize plant growth in crop production. Likewise, the results suggested that crop grown under sandy soil managed with organic materials perform better in term of plant growth and yield development. However, because of the fact that this study has not provide an account of dry matter and yield weight of the maize crop at the end of the experiment, we are unable to suggest the best organic material for economic crop production under soil quality and soil fertility benefits to crop production. However, it is believe that all the organic materials used are important source of essential soil nutrients for plant growth and yield performances.

\section{Acknowledgement}

The authors acknowledge research funding from Kebbi State Nigeria under the leadership of Alhaji Usman Saidu Nasamu Dakin-gari government. The original results of this paper was collected by Suleiman Usman as part of his PhD research activities, therefore, we show our gratitude to him and wish him a superior success in finishing his program at Natural Resources Institute, the University of Greenwich, UK.

\section{Reference}

[1] B. Jeffrey, Fact Sheet: Why Soil Organic Matter matters. Soil Carbon and Nitrogen Balance in Agricultural Lands. Land and Water and Sustainable Agriculture Flagship. (Commonwealth Scientific and Industrial Research Organisation (CSIRO), 2008).

[2] Berner, I. Hildermann, A. Fließbach, L. Pfiffner, U. Niggli, P. Mäder, Crop yield and soil fertility response to reduced tillage under organic management. Soil and Tillage Research, 2002, 101, (1-2), 89-96.

[3] H. Janssen, and R. van der Weert, The influence of fertilizers, soil organic matter and soil compaction on maize yields on the Surinam 'Zanderij' soils. Plant and Soil, 1977, 46:2, $445-458$.

[4] Vanlauwe, K. Aihou' S. Aman' E. N. O. Iwuafor' B. K. Tossah, J. Diels, N. Sanginga, O. Lyasse, R. Merckx, and J. Decker, Maize Yield as Affected by Organic Inputs and Urea in the West African Moist Savanna. Agronomy Journal, 2001, 93: 6, 1191-1199.

[5] McDonald, Soil organic matter, (The Department of Primary Industries, Parks, Water and Environment. Hobart, Tasmania, Australia, 2010).

[6] F. Caires, H. A. W. Joris, S. and Churka, Long-term effects of lime and gypsum additions on no-till corn and soybean yield and soil chemical properties in southern Brazil. Soil Use and Management, 2011, 27, 45-53.

[7] FAO, Guidelines for Soil Descriptions 5th ed. (FAO, Rome, Italy, 2006).

[8] FAO, The importance of soil organic matter: key to drought-resistant soil and sustained food production: FAO Soil Bulletin. (Natural Resources Management and Environment Department, FAO. 94 pp, 2005).

[9] J. Nacson, Data Analysis and Interpretation: From Various Internet Websites. (Culled, SDSU Educational Technology, Kathleen Barlo, 2007).

[10] J. van Etten, and de Bruin, Regional and local maize seed exchange and replacement in the western highlands of Guatemala. Plant Genetic Resources, 2007, 5: 57-70.

[11] J. Verzani, Simple-R: Using $\mathrm{R}$ for Introductory Statistics. (CSI Math department. Available at: http://www.math.csi.cuny.edu/Statistics/R/simpleR, 2002).

[12] KARDA (2009) Soil and Environmental Information in Kebbi State, (Kebbi Agricultural and Rural Development Authority (KARDA), Kebbi State Nigeria, 2009).

[13] L. B. Badstuea, M. R. Bellona, J. Berthauda, A. Ramíreza, D. Floresa, and X. Juárezd, The Dynamics of Farmers' Maize Seed Supply Practices in the Central Valleys of Oaxaca, Mexico. World Development, 2007, 35: 9, $1579-1593$.

[14] L. L. Tieszen, G. G. Tappanb, A. and Touréc, Sequestration of carbon in soil organic matter in Senegal: an overview. Journal of Arid Environments, 2001, 59, (3), 409-425.

[15] M. Basu, P. B. S. Bhadoria, and S. C. Mahapatra, Comparative effectiveness of different organic and industrial wastes on peanut: plant growth, yield, oil content, proteint content, mineral composition and hydration coefficient of kernels. Archives of Agronomy and Soil Science, 2007, 53: 6, 645-658.

[16] M. Put, J. Verhagen, E. Veldhuizen, and P. Jellema, Climate Change in Dryland West Africa?: The empirical evidence of rainfall variability and trends. Environment and Policy, 2004, 39, 27-32.

[17] M. S. Fan, S. H. Lu, R. F. Jiang, J. Six, and F. S. Zhang, Long -term non-flooded mulching cultivation influences rice productivity and soil organic carbon, Soil Use Management, 2012, 28, $544-550$.

[18] M. Upton, African farm management, (Cambridge University Press, Cambridge New York. Pp 179, 1987).

[19] O. Omotayo and Chukwuka, Soil fertility restoration techniques in sub-Saharan Africa using organic resources. African Journal of Agricultural Research, 2009, 4 (3) $144-150$.

[20] P. Mäder, A. Fliessbach, D. Dubois, L. Gunst, P. Fried, U. Niggli, Soil fertility and biodiversity in organic farming. Science, 2002, 296, 1694-169.

[21] S. Usman, Understanding Soils: Environment and Properties under Agricultural Conditions. (Publish America, Baltimore, USA. ISBN (Book): 9781627098533. $151 \mathrm{pp}, 2013$ ).

[22] S. Usman, S. S. Noma, M. Abdullahi, and A. Aminu, Assessment of farmer's perception on soil quality deteriorating and crop yield reduction in Sudan Savannah of Sub-Saharan Africa by 2020. International Achieve for Library and Information Science, E-LIS, 2012, http://hdl.handle.net/10760/18084, 5679: (4), 1-12.

[23] S. Usman, Sustainable soil management of the dryland soils of northern Nigeria (GRIN Publishing GmbH, Munich, Germany. ISBN (Book): 978-3-640-92122-5. 155 pp, 2007).

[24] Soil Survey Staff, Keys to Soil Taxonomy. $11^{\text {th }}$ edn. (USDA-NRCS, Washington DC, 2010).

[25] Z. Maris, and J. Ryan, Soil organic matter and related physical properties in a Mediterranean wheat-based rotation trial. Soil and Tillage Research, 2006, 87, (2), 146-154. 


\begin{tabular}{|c|c|c|c|c|}
\hline \multicolumn{5}{|c|}{ Appendix } \\
\hline $\begin{array}{c}1 \text { week }\left(1^{\text {st }}\right. \\
\text { measurement })\end{array}$ & Stem height $(\mathrm{cm})$ & Leaf size $(\mathrm{cm})$ & Leaf length $(\mathrm{cm})$ & No. of leaf plant-1 \\
\hline S-cow01 & 0 & & 0 & 0 \\
\hline S-sheep02 & 5.1 & 1.3 & 15.6 & 4 \\
\hline S-goat03 & 5.1 & 1.1 & 16.5 & 4 \\
\hline S-donkey04 & 6.1 & 1.4 & 16.3 & 4 \\
\hline Rice husks05 & 5.7 & 1.8 & 16.5 & 4 \\
\hline S-millethusks06 & 5.3 & 1.8 & 17.3 & 5 \\
\hline S-albida07 & 6.6 & 1.3 & 19.6 & 4 \\
\hline S-nilotica08 & 6 & 1.1 & 18.5 & 4 \\
\hline S-ood-ash09 & 6.5 & 1.2 & 16.8 & 4 \\
\hline S-Wood-husk10 & 0 & 0 & 0 & 0 \\
\hline S-house refus11 & 6.5 & 1.5 & 20.5 & 4 \\
\hline S-ani-cro-ber12 & 8.1 & 1.7 & 22.2 & 5 \\
\hline SUN & 61 & 14.2 & 179.8 & 42 \\
\hline AVERAGE & 5.083333333 & 1.290909091 & 14.98333333 & 3.5 \\
\hline SD & 2.511730057 & 0.498907898 & 7.264963659 & 1.678744119 \\
\hline VARIANCE & 2.511730057 & 0.248909091 & 52.77969697 & 2.818181818 \\
\hline MAX & 8.1 & 1.8 & 22.2 & 5 \\
\hline MIN & 5.1 & 1.1 & 15.6 & 4 \\
\hline
\end{tabular}

\begin{tabular}{|c|c|c|c|c|c|}
\hline $\begin{array}{c}3 \text { weeks }\left(2^{\text {nd }}\right. \\
\text { measurement })\end{array}$ & $\begin{array}{l}\text { Stem height } \\
(\mathrm{cm})\end{array}$ & Stem size $(\mathrm{cm})$ & $\begin{array}{l}\text { Leaf length } \\
(\mathrm{cm})\end{array}$ & Leaf size $(\mathrm{cm})$ & No. of leaf plant-1 \\
\hline S-cow01 & 6.1 & 0.4 & 22.6 & 1.8 & 5 \\
\hline S-sheep02 & 8.2 & 0.6 & 30.1 & 2.2 & 6 \\
\hline S-goat03 & 9 & 0.7 & 32.4 & 3 & 7 \\
\hline S-donkey04 & 10.9 & 0.8 & 30.7 & 2.8 & 7 \\
\hline S-rice-husk05 & 8.4 & 0.7 & 30.6 & 2.7 & 7 \\
\hline S-millet-husk06 & 9.8 & 0.9 & 35 & 3.1 & 8 \\
\hline S-albida07 & 10.7 & 0.7 & 38.8 & 3.1 & 8 \\
\hline S-nilotica08 & 7.8 & 0.7 & 29.5 & 2.5 & 7 \\
\hline S-wood-ash09 & 10.7 & 0.7 & 36.1 & 2.7 & 6 \\
\hline S-wood-husk10 & 0 & 0 & 0 & 0 & 0 \\
\hline S-ouse-refuse11 & 8.5 & 0.9 & 37.9 & 2.9 & 8 \\
\hline S-ani-cro-ber12 & 11.8 & 0.9 & 38.4 & 3 & 8 \\
\hline SUN & 101.9 & 8 & 362.1 & 29.8 & 77 \\
\hline AVERAGE & 8.491666667 & 0.666666667 & 30.175 & 2.483333333 & 6.416667 \\
\hline SD & 3.116950238 & 0.253460893 & 10.59108759 & 0.872648355 & 2.234373 \\
\hline VARIANCE & 9.715378788 & 0.064242424 & 112.1711364 & 0.761515152 & 4.992424 \\
\hline MAX & 11.8 & 0.9 & 38.8 & 3.1 & 8 \\
\hline MIN & 6.1 & 0.4 & 22.6 & 1.8 & 5 \\
\hline
\end{tabular}

\begin{tabular}{|c|c|c|c|c|c|}
\hline $\begin{array}{c}5 \text { weeks }\left(3^{\text {rd }}\right. \\
\text { measurement })\end{array}$ & $\begin{array}{l}\text { Stem height } \\
(\mathrm{cm})\end{array}$ & Stem size $(\mathrm{cm})$ & $\begin{array}{l}\text { Leaf length } \\
(\mathrm{cm})\end{array}$ & Leaf size $(\mathrm{cm})$ & No. of leaf plant-1 \\
\hline S-cow01 & 12.3 & 1 & 46.7 & 3.8 & 8 \\
\hline S-sheep02 & 13.2 & 1.2 & 45.5 & 4 & 8 \\
\hline S-goat03 & 14.3 & 1.4 & 52.2 & 5.3 & 8 \\
\hline S-donkey04 & 14.4 & 1.4 & 51.8 & 4.5 & 8 \\
\hline S-rice-husk05 & 13.1 & 1.2 & 43.7 & 4.2 & 8 \\
\hline S-millet-husk06 & 16.9 & 1.6 & 54.3 & 5.1 & 9 \\
\hline S-albida07 & 14.6 & 1.2 & 53.4 & 4.8 & 8 \\
\hline S-nilotica08 & 12.5 & 1.3 & 46.7 & 4.7 & 8 \\
\hline S-wood-ash09 & 15.2 & 1 & 52.6 & 4.1 & 7 \\
\hline S-wood-husk10 & $\#$ & \# & $\#$ & $\#$ & $\#$ \\
\hline S-house-refus11 & 15 & 1.3 & 53.1 & 4.5 & 10 \\
\hline S-ani-cro-ber12 & 18.1 & 1.4 & 58.6 & 5.2 & 8 \\
\hline SUN & 159.6 & 14 & 558.6 & 50.2 & 90 \\
\hline AVERAGE & 14.50909091 & 1.272727273 & 50.78181818 & 4.563636364 & 8.181818182 \\
\hline SD & 1.789108463 & 0.179392916 & 4.510613746 & 0.506503163 & 0.750757194 \\
\hline VARIANCE & 3.200909091 & 0.032181818 & 20.34563636 & 0.256545455 & 0.563636364 \\
\hline MAX & 18.1 & 1.6 & 58.6 & 5.3 & 10 \\
\hline MIN & 12.3 & 1 & 43.7 & 3.8 & 7 \\
\hline
\end{tabular}


Weekly performance of maize plant under sandy-soil managed with dissimilar organic materials

\begin{tabular}{|c|c|c|c|c|c|}
\hline $\begin{array}{c}7 \text { weeks }\left(4^{\text {th }}\right. \\
\text { measurement) }\end{array}$ & $\begin{array}{l}\text { Stem height } \\
(\mathrm{cm})\end{array}$ & Stem size $(\mathrm{cm})$ & $\begin{array}{l}\text { Leaf length } \\
(\mathrm{cm})\end{array}$ & Leaf size $(\mathrm{cm})$ & No. of leaf plant-1 \\
\hline S-cow01 & 34.1 & 1.7 & 57.9 & 5.3 & 9 \\
\hline S-sheep02 & 35.4 & 1.6 & 60 & 5.6 & 9 \\
\hline S-goat03 & 38.2 & 2.1 & 66.3 & 6.5 & 12 \\
\hline S-donkey04 & 46.3 & 2.1 & 75 & 7.8 & 12 \\
\hline S-rice-husk05 & 34 & 1.5 & 59.4 & 5 & 10 \\
\hline S-millet-husk06 & 52.6 & 2.4 & 69.8 & 7.2 & 12 \\
\hline S-albida07 & 35.7 & 1.5 & 61.6 & 6.1 & 10 \\
\hline S-nilotica08 & 33 & 1.5 & 56.8 & 5.8 & 9 \\
\hline S-wood-ash09 & 33.6 & 1.7 & 64.5 & 6.2 & 12 \\
\hline S-wood husk10 & $\#$ & \# & $\#$ & $\#$ & $\#$ \\
\hline S-house-refus11 & 38.2 & 1.6 & 63 & 5.3 & 10 \\
\hline S-ani-cro-ber12 & 46.1 & 2.2 & 76.2 & 7 & 12 \\
\hline SUN & 427.2 & 19.9 & 710.5 & 67.8 & 117 \\
\hline AVERAGE & 38.83636364 & 1.809090909 & 64.59090909 & 6.163636364 & 10.63636364 \\
\hline SD & 6.539613555 & 0.326969557 & 6.619283125 & 0.886873979 & 1.361816968 \\
\hline VARIANCE & 42.76654545 & 0.106909091 & 43.81490909 & 0.786545455 & 1.854545455 \\
\hline MAX & 52.6 & 2.4 & 76.2 & 7.8 & 12 \\
\hline MIN & 33 & 1.5 & 56.8 & 5 & 9 \\
\hline
\end{tabular}

\begin{tabular}{|c|c|c|c|c|c|}
\hline $\begin{array}{c}10 \text { weeks }\left(5^{\text {th }}\right. \\
\text { measurement) }\end{array}$ & $\begin{array}{l}\text { Stem height } \\
(\mathrm{cm})\end{array}$ & Stem size $(\mathrm{cm})$ & $\begin{array}{l}\text { Leaf length } \\
(\mathrm{cm})\end{array}$ & Leaf size $(\mathrm{cm})$ & No. of leaf plant-1 \\
\hline S-cow01 & 76.7 & 2 & 62.2 & 6.2 & 12 \\
\hline S-sheep02 & 63.5 & 2.1 & 66.8 & 6.7 & 10 \\
\hline S-goat03 & 69 & 2.7 & 70.3 & 7.2 & 10 \\
\hline S-donkey04 & 90.3 & 2.2 & 79.7 & 7.8 & 12 \\
\hline S-rice-husk05 & 58.2 & 2 & 66.2 & 6.1 & 12 \\
\hline S-millethusk06 & 120 & 2.8 & 78 & 7.4 & 12 \\
\hline S-albida07 & 78.8 & 2.1 & 61.3 & 6.6 & 11 \\
\hline S-nilotica08 & 78.4 & 2.2 & 60.8 & 6.1 & 11 \\
\hline S-wood-ash09 & 54.4 & 1.9 & 71.2 & 6.3 & 12 \\
\hline S-woodhusk10 & $\#$ & $\#$ & $\#$ & $\#$ & $\#$ \\
\hline S-houserefus11 & 82.3 & 2.5 & 69 & 6.2 & 12 \\
\hline S-ani-cro-ber12 & 113 & 2.6 & 78.1 & 7.2 & 12 \\
\hline SUN & 884.6 & 25.1 & 763.6 & 73.8 & 126 \\
\hline AVERAGE & 80.41818182 & 2.281818182 & 69.41818182 & 6.709090909 & 11.45455 \\
\hline SD & 20.82593663 & 0.31246818 & 6.843656652 & 0.599090219 & 0.8202 \\
\hline VARIANCE & 433.7196364 & 0.097636364 & 46.83563636 & 0.358909091 & 0.672727 \\
\hline MAX & 120 & 2.8 & 79.7 & 7.8 & 12 \\
\hline MIN & 54.4 & 1.9 & 60.8 & 6.1 & 10 \\
\hline
\end{tabular}

\begin{tabular}{|c|c|c|}
\hline Yield assessment (after harvest) & Number of line corn-1 & Number of seed corn-1 \\
\hline Cow & 13 & 581 \\
\hline Sheep & 12 & 608 \\
\hline Goat & 16 & 616 \\
\hline Donkey & 14 & 564 \\
\hline Rice husks & 12 & 700 \\
\hline Millet husks & 20 & 611 \\
\hline Acacia albida & 13 & 440 \\
\hline Acacia nilotica & 10 & 518 \\
\hline Wood ash & 14 & 696 \\
\hline Wood husk & $\#$ & 846 \\
\hline House refused & 12 & 6756 \\
\hline Ani-cro-ber & 18 & 614.1818182 \\
\hline SUN & 154 & 106.0743307 \\
\hline AVERAGE & 14 & 11251.76364 \\
\hline SD & 2.93257566 & 846 \\
\hline VARIANCE & 8.6 & 440 \\
\hline MAX & 20 & \\
\hline MIN & 10 & \\
\hline
\end{tabular}

